re vista docência do ensino

\title{
Visões de professores formadores sobre a formação e exercício da docência do professor de química
}

\author{
Gabrielle Gomes Ferreira ${ }^{1}$, \\ Thiago Antunes-Souza ${ }^{2}$
}

\section{RESUMO}

A presente investigação insere-se no campo de estudos e pesquisas da formação de professores, focalizando em especial a formação de educadores químicos. Nesse contexto, apresenta-se como objetivo entender a função do professor de química em sua profissionalidade, à luz das compreensões dos docentes de um curso de licenciatura em Ciências de uma universidade pública do estado de São Paulo. Para tanto, com base em pressupostos da pesquisa qualitativa, foram entrevistados seis professores formadores por meio de entrevistas semiestruturadas. As análises foram construídas a partir dos seguintes eixos: i) Entendimento sobre o que é ser professor de química; ii) A profissão forjada na própria trajetória de vida. Os resultados apontam para a valorização da formação inicial, para a relevância das relações aluno-professor e para o entendimento do professor sobre sua identidade profissional.

Palavras-chave: Formação de professores. Educação química. Professor formador.

\section{Como citar este documento - ABNT}

FERREIRA, Gabrielle Gomes; ANTUNES-SOUZA, Thiago. Visões de professores formadores sobre a formação e exercício da docência do professor de química. Revista Docência do Ensino Superior, Belo Horizonte, v. 11 e034573, p. 1-18, 2021. DOI: https://doi.org/10.35699/2237-5864.2021.34573.

\footnotetext{
${ }^{1}$ Universidade Federal de São Paulo (Unifesp), Diadema, SP, Brasil. ORCID ID: https://orcid.org/0000-0002-8467-8729. E-mail: ferreira.gabriellegomes@gmail.com

2 Universidade Federal de São Paulo (Unifesp), Diadema, SP, Brasil. ORCID ID: https://orcid.org/0000-0002-5881-8855. E-mail: tasouza@unifesp.br
} 


\section{Visiones de profesores formadores sobre la formación y ejercicio de la docencia del profesor de química}

\section{RESUMEN}

Esta investigación forma parte del campo de los estudios e investigaciones de la formación del profesorado, centrándose especialmente en la formación del educador químico. En este contexto, tiene como objetivo analizar el papel del profesor de química en su profesionalidad, a la luz de los entendimientos de los formadores en un curso de licenciatura en Ciencias de una universidad en el estado de São Paulo. Para ello, apoyado por supuestos de investigación cualitativa, se entrevistó a seis formadores de profesores a través de entrevistas semiestructuradas. Los análisis se construyeron a partir de los siguientes ejes: i) Comprensión de lo que es ser profesor de química; ii) La profesión forjada en la propia trayectoria de vida. Los resultados apuntan a la valorización de la formación inicial, a la relevancia de las relaciones alumno-profesor y a la comprensión del profesor sobre su identidad profesional.

Palabras clave: Formación de profesores. Educación química. Formador de profesores.

\section{Teacher trainer's point of view about the training and teaching practice of the chemistry teacher}

\section{ABSTRACT}

This research is part of the teacher training studies field, focusing the chemical educators training. In this context, it aims to analyze the role of the chemistry teacher in his professionality, from the perspective of the teacher trainers of the Science course degree at a university in the state of São Paulo. Therefore, supported by assumptions of qualitative research, six teacher trainers were interviewed through semi-structured interviews. The analyzes were built from the following axes: i) Understanding about what it means to be a chemistry teacher; ii) The profession forged in the life trajectory. The results point to the appreciation of initial training, to the relevance of student-teacher relationships and to the teacher's understanding about your own professional identity.

Keywords: Teacher training. Chemical education. Teacher trainer. 


\section{INTRODUÇÃO}

O presente trabalho está inserido no campo de estudos e pesquisas da formação de professores e tem como objetivos trazer contribuições às investigações sobre a formação de professores de química. Desta forma, em diálogo com esse campo, encontramos, em um mapeamento sobre a pesquisa no campo da formação de professores de química no Brasil realizado por Silva e Queiroz (2016), características que nos ajudaram a delimitar o nosso objetivo de pesquisa.

Nesse estado da arte sobre o campo, os autores analisaram 104 dissertações e 33 teses defendidas em programas de pós-graduação em química, educação e em ensino de ciências e matemática no Brasil entre 2001 e 2010. Dentre vários outros aspectos, nos seus resultados foram destacados os temas sobre a formação inicial $(53,3 \%$ de todos os trabalhos) e o desenvolvimento profissional contínuo (36,5\% de todos os trabalhos) como os mais pesquisados no período analisado (SILVA; QUEIROZ, 2016).

Assim, os autores sinalizam que os estudos sobre a "formação de professores de Química ainda se concentram na formação inicial e continuada, indicando a necessidade de novas frentes de investigação" (SILVA; QUEIROZ, 2016, p. 71). A partir dos resultados, entendemos como contributivo um estudo que envolvesse a profissionalização docente, por ser um tema pouco estudado na área segundo o mencionado estado da arte, e que contemplasse também os professores formadores.

Escolhemos esse perfil por reconhecer que existem poucos trabalhos envolvendo-o, como evidenciou o estado da arte, e por concordar com a afirmação de Belo e Gonçalves (2012, p. 300) quando os autores dizem que os professores formadores "são atores essenciais quando tratamos da formação dos futuros docentes [...], pois, são profissionais que atuam diretamente na formação dos licenciandos, e que servem ou não de modelos de um 'bom' professor".

Nesse sentido, a presente pesquisa foi construída buscando entender a função do professor de química em sua profissionalidade, à luz das compreensões dos docentes de um curso de licenciatura em Ciências de uma universidade pública do estado de São Paulo, quanto à formação de professores de química. Assim, a questão de investigação desta pesquisa foi: $A$ partir de sua própria trajetória de formação e atuação no curso de licenciatura, como professores formadores entendem o profissional docente e sua formação?

Para alcançar o objetivo proposto, foram entrevistados seis professores formadores pertencentes à trajetória de química e que ministram disciplinas específicas ou pedagógicas da área de química para aquele curso. 


\section{CONSIDERAÇÕES ACERCA DO PAPEL DO PROFESSOR}

As constantes mudanças sociais têm influência direta na educação, na escola e, principalmente, na atividade do professor (MARCELO, 2009). No campo do ensino, diversas são as definições para o "ser professor" e suas competências. Essa pluralidade de concepções deve-se à dificuldade de definir outros fatores do exercício profissional, como sua formação, sua constituição profissional e o próprio ato de ensinar (MENDES; BACCON, 2015; ROLDÃO, 2007).

Mendes e Baccon (2015), por exemplo, problematizam a atuação profissional do professor na "sociedade do conhecimento" (sociedade atual) e a defendem como atividade política que contribui para a formação dos cidadãos: "[...] ao professor é almejado que ele contribua para uma melhora qualitativa da sociedade, o que só se faz quando há o compromisso político-social na docência para a formação cidadã dos sujeitos" (MENDES; BACCON, 2015, p. 39786-39787).

Nesse contexto, o professor pode ser caracterizado como um profissional que trabalha com o conhecimento, e, para tanto, necessita ter compromisso com a aprendizagem discente. Apoiadas em Nóvoa (1995), Mendes e Baccon (2015) descrevem que o desenvolvimento docente deve englobar três dimensões: i) a pessoal, que propõe um estímulo a reflexões críticas e uma maior autonomia para a construção de sua identidade; ii) a profissional, que coloca o professor como "autor e produtor da sua profissão" (MENDES; BACCON, 2015, p. 39789), e, por fim; iii) a organizacional, que diz respeito aos projetos escolares cujo desenvolvimento está diretamente ligado ao desenvolvimento das outras duas dimensões.

Assim, as autoras argumentam que o desenvolvimento profissional docente não está apenas alicerçado na tarefa de ensinar, mas no esforço contínuo e necessário de continuar aprendendo a ensinar. Nessa direção, distinguem o "ser professor" do "ser professor e ensinar", afirmando que a formação para a segunda definição só é possível a partir de um processo de formação em continuum e que o docente se constrói por um processo de “desenvolvimento da capacidade de reflexão" (MENDES; BACCON, 2015, p. 39788).

Considerando a relevância da capacidade reflexiva e crítica do professor em sua profissionalidade, Roldão (2007, p. 94) advoga que a atividade docente "trata-se de uma construção histórico-social em permanente evolução", o que exige, dos sujeitos da área, uma avaliação constante do que constitui suas particularidades. Desse modo, além da dificuldade de dar significado ao ato de "ensinar" e de definir a complexidade da função do professor, seu histórico mutável e suas diversificadas correntes teóricas "empurram a função de ensinar ora para a indefinição ora para a tecnicização" (ROLDÃO, 2007, p. 97). 
Segundo Nóvoa (1995), a atividade de ensinar é anterior à necessidade de uma formação própria para se ensinar, o que reflete negativamente na atividade docente, uma vez que essa característica contribui para retardar a afirmação e a identificação dos professores como um grupo profissional pela sociedade. No entanto, a constante teorização sobre a ação de ensinar gerou estudos das práticas que transformaram o modelo de atuação profissional.

Formalizado o conhecimento profissional, há a necessidade da organização de saberes inerentes ao professor, que correspondem ao saber teórico e prático (científico, científicodidático e pedagógico). O saber teórico é caracterizado como: "saber produzido e formalizado pela investigação sobre a prática de ensinar" (ROLDÃO, 2007, p. 98), bem como pelo "conhecimento teórico produzido ou mobilizado pelos actores na prática de ensinar" (ROLDÃO, 2007, p. 98). Por sua vez, o saber prático pode ser entendido como: "o saber fazer, saber como fazer, e saber porque se faz" (ROLDÃO, 2007, p. 98).

Para estar apto a se adaptar às constantes mudanças de sua profissão, o professor precisa desenvolver a capacidade de relacionar saberes práticos e teóricos, formando um elo entre a realidade social e o saber científico e/ou intelectual. Desta forma, como profissional em constante formação (e que se desenvolve, também, na prática), deve, antes de tudo, estar intimamente envolvido em seu processo formativo individual, para que estabeleça relações entre experiências anteriores e os novos conhecimentos:

[...] a prática pedagógica é aprendida por meio da inseparável relação entre teoria e prática e não apenas com a teoria. Então, entendemos que o docente se constitui a partir do momento em que se vivencia a relação dialética do processo de ensino e de aprendizagem, entre a concretude da sala de aula e os estudos acadêmicos na universidade (MENDES; BACCON, 2015, p. 39789).

Isso auxiliaria na construção permanente de uma identidade profissional, para não caírem numa rotina de aplicação da teoria como técnica pré-estabelecida e perderem a profissionalidade (MENDES; BACCON, 2015). Ao contrário, o saber profissional docente deve estar intimamente atrelado à articulação da teoria com a prática, já que se baseia em teorias que são ressignificadas na prática docente no seu contexto social de atuação, e reelaboradas para, assim, fundamentar o ato de ensinar.

Nesses termos, concordamos com Garcia, Hypólito e Vieira (2005, p. 48) quando os autores defendem que a identidade profissional docente é construída socialmente e marcada por aspectos sociais, históricos, culturais, políticos e econômicos presentes no tecido formativo pessoal e profissional do professor. Não obstante, a formação inicial tem lugar privilegiado na constituição da profissionalidade, na medida em que: 
[...] a formação inicial de professores tem importância ímpar, uma vez que cria as bases sobre as quais esse profissional vem a ter condições de exercer a atividade educativa na escola com as crianças e os jovens que aí adentram, como também, as bases de sua profissionalidade e da constituição de sua profissionalização. Essa formação, se bem realizada, permite à posterior formação em serviço ou aos processos de educação continuada avançar em seu aperfeiçoamento profissional (GATTI; BARRETTO; ANDRÉ, 2011, p. 89).

Nessa perspectiva, a formação inicial precisa considerar ações a partir das quais os licenciandos tenham acesso aos conhecimentos pedagógicos relacionados ao conteúdo específico de sua área de formação, visando a formação profissional no sentido mais amplo do termo, ou seja, a formação para o exercício de uma profissão.

Assim, acreditamos que aos formadores de professores cabe a responsabilidade de introduzir os futuros profissionais num campo de pensamento preocupado com a docência, o que exigirá mais do que o domínio do conteúdo a ser ensinado: "é preciso que toda a formação seja influenciada pela dimensão profissional, não num sentido técnico ou aplicado, mas na projeção da docência como profissão baseada no conhecimento" (NÓVOA, 2017, p. 1116). Portanto, discutir sua profissionalidade é incorporar os diversos fatores que influenciam, direta ou indiretamente, em sua construção e, por esta razão, elegemos docentes de um curso de formação inicial como participantes da pesquisa.

Por fim, ressaltamos que será em diálogo com essa perspectiva teórica que os relatos dos formadores entrevistados serão analisados, compreendendo a estreita relação da trajetória de vida com as experiências de formação existentes na construção do profissional docente.

\section{ESCOLHAS METODOLÓGICAS}

Esta pesquisa de natureza qualitativa tem por propósito a compreensão, a explanação e a especificação do fenômeno e opta por definições que envolvem o processo, conceitos que se apontam via propriedades e por uma amostra pequena escolhida seletivamente (SANTOS FILHO, 2002).

Para alcançar o objetivo proposto, foram entrevistados seis professores do curso de licenciatura em Ciências pertencentes à trajetória de química e que ministram disciplinas específicas ou pedagógicas da área de química. A escolha dos sujeitos participantes se deu, ainda, por meio dos seguintes critérios: i) ser professor efetivo do curso de Ciências da instituição em que ocorreu a pesquisa; ii) aceitar participar voluntariamente.

As entrevistas foram desenvolvidas de forma semiestruturada. Esse modelo de entrevista pode ser definido como um tipo que "combina perguntas fechadas e abertas, em que o 
entrevistado tem a possibilidade de discorrer sobre o tema em questão sem se prender à indagação formulada" (MINAYO, 2008, p. 64). Acreditamos que o uso de entrevistas se mostra relevante para a temática estudada, na medida em que, como explicita Miguel (2012, p. 3), é um instrumento de inter-relacionamento humano que permite: "buscar tentativas de compreender a experiência de outras pessoas e os significados que elas atribuem a essas experiências".

A construção das questões seguiu as orientações de Roldão (2007), que delimitam a relevância de se analisar as ações de ensinar, em vez de tentar compreender apenas a prática docente. Nesse sentido, pensar as ações dos professores, baseando-se em seus saberes formais e experienciais, proporciona um aprofundamento em seus saberes específicos. Assim, o roteiro de entrevista foi dividido em duas partes: na primeira, respeitando o princípio de anonimato do entrevistado, utilizamos apenas questões gerais para compreensão de quem é o sujeito no curso e sua trajetória profissional, sem identificar seu nome ou disciplina ministrada, e, na segunda parte da entrevista, trabalhamos com questões pertinentes ao objeto desta pesquisa.

Para a construção das análises, as entrevistas foram transcritas e lidas várias vezes de modo que fosse possível a escolha de trechos de falas dos entrevistados que representassem em maior ou menor grau suas experiências formativas e de atuação que nos possibilitassem responder à questão de investigação: $A$ partir de sua própria trajetória de formação $e$ atuação no curso de licenciatura, como professores formadores entendem o profissional docente e sua formação?

Na tentativa de apreensão dos sentidos manifestados nos discursos dos professores entrevistados, nos apoiamos nas contribuições de Bardin (2004) para codificação e categorização dos trechos das entrevistas. No momento da codificação, enumeramos excertos em unidades significativas de assuntos comuns, tal como a autora define: "a codificação corresponde a uma transformação efetuada segundo regras precisas dos dados em bruto do texto, transformação esta que, recorte, agregação e enumeração, permite atingir uma representação de conteúdo" (BARDIN, 2004, p. 97).

Dessa forma, a partir das escolhas dos trechos das entrevistas, guiados pela questão de investigação, por meio da codificação, categorizamos nossos resultados em dois eixos de análise: i) Entendimento sobre o que é ser professor de química e ii) A profissão forjada na própria trajetória de vida. Tal ação foi iluminada pelas contribuições do campo de formação de professores discutidas na seção anterior. Classificamos os excertos em conjuntos, assim como Bardin (2004, p. 111) define: “As categorias são rubricas ou classes, que reúnem um grupo de elementos sob um título genérico, agrupamento esse efetuado em razão das características comuns destes elementos". No primeiro eixo, destacamos de que modo os 
professores entendem a função e a formação do professor de química. No segundo eixo, focalizamos a própria trajetória de formação e a atuação dos professores entrevistados para entendermos como eles compreendem a própria atuação no curso de licenciatura e como se constituíram professores.

Destacamos, por fim, que este trabalho foi aprovado pelo Comitê de Ética em Pesquisa da Universidade Federal de São Paulo, sob o número CAAE 39225320.8.0000.5505 e que todos os participantes assinaram o Termo de Consentimento Livre e Esclarecido (TCLE).

\section{OS SUJEITOS DE ANÁLISE}

O perfil dos sujeitos que participaram desta pesquisa foi delimitado de acordo com sua própria apresentação na primeira etapa da entrevista. Em respeito ao anonimato dos docentes, seus nomes foram alterados e são elencados a seguir:

Clara é formada em Química, licenciatura, é mestre em Ciências e Engenharia de Materiais (química e física), doutora em Ciências e pós-doutora em Físico-Química de Superfícies. Atuou 12 anos na educação básica e está há 7 anos no ensino superior. Aplica-se ao ensino e pesquisa científica e suas pesquisas estão centradas no ensino de ciências e físico-química de superfícies.

Cássia possui graduação em licenciatura em Química, mestrado e doutorado na área de tecnologia nuclear e pós-doutorado em Educação Ambiental. Atua como docente do ensino superior há 10 anos e tem como foco de pesquisa a educação ambiental e a psicologia ambiental.

Rúbia é graduada em licenciatura e bacharelado em Química, tem doutorado e pósdoutorado em Química Orgânica e sua pesquisa mantém-se nesta área com enfoque em síntese orgânica. Trabalha no ensino superior há 8 anos.

Túlio graduou-se em licenciatura e bacharelado em Química e licenciatura em Pedagogia, é mestre em História Social e doutor em Educação. Atua na área de química e história da educação, sendo a última o foco de suas pesquisas, com ênfase para a história do ensino de ciências. É professor do ensino superior há 10 anos.

Rute possui graduação em licenciatura em Química, é mestre e doutora em Ciências (química analítica) e pós-doutora em Química Analítica. Atua no ensino de química analítica e experimentação no ensino de química, área que é também seu objeto de pesquisa, bem como a percepção pública em ciência e tecnologia e divulgação científica. Ministra aulas para o ensino superior há 10 anos. 
Lídia graduou-se em Engenharia Química e complementou sua formação com a licenciatura em Química, é mestre e doutora em Ensino de Ciências e possui pós-doutorado em Educação. Atua na área de ensino de ciências (química) e dedica-se à pesquisa sobre a formação inicial de professores. Leciona para o ensino superior há 9 anos.

\section{ENTENDIMENTO SOBRE O QUE É SER PROFESSOR DE QUÍMICA}

Um dos primeiros questionamentos feitos aos formadores foi sobre quais saberes o docente formador deveria deter para formar professores. Trazemos a seguir algumas falas:

"Acredito que uma valorização da química verde e da área de humanas no currículo, particularmente, a filosofia e ciências sociais. A partir destes conhecimentos é possivel formar um futuro profissional com conhecimento técnico e humano mais alinhado com os complexos desafios socioambientais do século XXI" (Cássia).

"É preciso conhecer a química para saber escolher o que é importante e o que é supérfluo; é preciso conhecer a didática, a história da educação, o contexto em que se vai atuar. É preciso ter sensibilidade para entender $o$ outro, saber ouvir, saber que o seu conhecimento é mais um que vai se integrar naquela cultura já existente" (Túlio).

"Para formar um professor é preciso compreender a complexidade dessa formação e buscar maneiras de viabilizar o aprendizado do discente nas diversas áreas. Além disso, durante a formação dos estudantes é preciso ter ciência que, com seu exemplo de professor, você está contribuindo para a visão de profissional deles" (Rute).

"Ter conhecimento sólido sobre os conteúdos, química experimental e as metodologias para poder trabalhar com os alunos as possibilidades de interação sobre estes conteúdos" (Rúbia).

"Conteúdo de química, obviamente, além disso, compreender no íntimo as relações sala de aula-escola-professor-aluno-responsáveis-direção, compreender mecanismos de aprendizagem, compreender metodologias $e$ suas aplicações em distintas realidades, compreender o ser humano e suas relações sociais. Formar um professor de Química vai muito além do conteúdo de química, o qual é a base para o início do processo" (Clara).

A partir desses trechos, podemos indicar que as concepções dos entrevistados tendem para uma correlação entre o modo de agir e o modo de formar e, desta maneira, os conceitos apresentados pelos professores formadores propõem uma concordância entre quem eles são e os tipos de profissionais que esperam formar.

Apesar de certas similaridades, cada professor tem um entendimento diferente do outro, bem como previu a professora Lídia em sua entrevista ao dizer: 
"Acho que para cada formador a resposta é diferente, cada um tem um ideal de professor" (Lídia).

Se cotejarmos as identificações dos sujeitos e suas falas, podemos constatar que cada docente cita seus ideais e suas concepções partindo de suas próprias vivências e de sua formação.

Sobre a formação de professor, há um consenso entre os autores do campo de que sua formação não começa e nem termina na formação inicial, ou seja, o professor se forma desde o momento que ingressa na escola, como aluno, e segue por toda sua vida escolar e durante a prática docente (MENDES; BACCON, 2015; MUNSBERG; SILVA, 2014; NÓVOA, 1992; ROLDÃO, 2007; SCHNETZLER; ANTUNES-SOUZA, 2018; TARDIF, 2005; VALLE, 2006). Desta maneira, podemos afirmar que a identidade do professor formador vai se construindo na sua formação e ao longo de sua atuação profissional em diálogo com o contexto sóciohistórico em que vive e com as pessoas a sua volta (alunos, colegas de trabalho, professores etc.).

Na entrevista com os professores formadores, a partir da reflexão do tipo de professor que se espera formar, os docentes participantes apresentaram suas noções sobre suas influências em seus alunos que serão futuros professores. Quando questionados se consideravam-se uma referência para os seus alunos, eles se posicionaram da seguinte maneira:

"Sim, certamente! Não necessariamente em questão de conteúdo, mas no sentido do tratamento, de entender que o aluno é um ser humano, nas relações aluno-professor, e o que é uma avaliação e o que é preciso avaliar" (Clara).

"Eu tento ser. Alguns estudantes já me disseram que me veem como referência por conta de alguns fatores como a preocupação com a aprendizagem do estudante, adequar o conteúdo ao objetivo da aula... Mas o maior fator é a empatia, porque você tem que entender o aluno! E com o tempo você também se forma, é uma via de mão dupla..." (Rute).

"Acredito que a gente sempre acaba sendo uma referência (boa ou ruim), mesmo sem perceber. O que procuro sempre é agir de acordo com o meu discurso, assim entre o que falo e faço sempre existe coerência" (Lídia).

"Na verdade, eu não sei, eu faço o melhor que posso. Acredito que alguns estudantes reconhecem algumas práticas que desenvolvo como bem pertinentes. Eu tenho uma ideia sobre a educação em química, tenho algumas coisas que acredito, como, por exemplo, o ensino não deve ser conteudista, a gente deve respeitar o amadurecimento cognitivo das pessoas... Acho que o ensino deve ser algo muito dialogado! E acho que pode ser uma referência para quem tá se formando como professor" (Túlio). 
"Na área de educação ambiental sim, eu apresento os diferentes discursos, visões e métodos da educação ambiental, e assim eu ensino meus alunos a conhecerem as diferentes correntes e práticas... Para eles atuarem com diferencial e é por isso que eu me considero uma referência para eles" (Cássia).

Os docentes acreditam ser uma referência para os seus alunos, dando destaque para as relações humanas de suas práticas em sala de aula, expressando novamente a noção de aprendizagem pelo exemplo. Sobre essa construção de identidade docente que passa pelo outro, Munsberg e Silva (2014) assumem que a incorporação pela observação da ação de seus professores é natural na formação docente. Porém, um relato se sobressai:

"Não me vejo como referência por não ser pesquisadora da área de ensino de química" (Rúbia).

Sua visão expõe um aspecto evidenciado na pesquisa de Schnetzler e Antunes-Souza (2018) quando analisam o desenvolvimento da pesquisa em ensino e o seu reconhecimento no campo científico da química. Segundo os autores, existe forte influência do habitus dos químicos que pesquisam no campo da química e que não se reconhecem como educadores em química, mesmo atuando em cursos de licenciatura, pois não pesquisam na área de ensino. Desta forma, entre os professores daquelas chamadas disciplinas específicas, é comum que eles tragam marcas de seu campo de formação e atuação para as suas aulas.

\section{A PROFISSÃO FORJADA NA PRÓPRIA TRAJETÓRIA DE VIDA}

Quando questionados sobre suas referências profissionais, os docentes apontaram momentos de sua formação e atuação em que o contato com outros professores possibilitou uma aprendizagem ou uma avaliação sobre sua prática. As seguintes respostas destacam esse caráter:

"Sim. Minha referência inicial foi minha professora de Química do ensino médio. Depois tive algumas referências de professores durante a graduação e pós (referências boas e ruins - essas que eu não queria seguir)" (Rute).

"Não positiva, mas tive alguns professores que foram exemplos do tipo de professora que eu não gostaria de me tornar" (Cássia).

Para Clara e Lídia as referências citadas são professores da graduação e da pós-graduação. Assim como as entrevistadas supracitadas, foi por meio desse contato que tomaram para si exemplos do que representava uma boa atuação docente ou um desempenho ruim. Considera-se que:

$\mathrm{Na}$ sala de aula, interagem professor/a e alunos/as, construindo-se mutuamente no processo de ensino-aprendizagem. Ambos/as aprendem, 
todos/as se formam, se constituem. Todos/as incorporam conhecimentos, valores e experiências. São vidas em formação, constantemente (MUNSBERG; SILVA, 2014, p. 6).

Professor Túlio, por sua vez, guia sua referência para uma situação em que já atuava na educação básica.

"No início da minha carreira, trabalhei em um curso supletivo no qual tive muitas experiências importantes. Destaco os professores de Física e Biologia, que muito antes da LDB/96 já trabalhavam com as ideias de contextualização e de interdisciplinaridade no ensino, e uma professora de Língua Portuguesa que desenvolvia projetos muito interessantes" (Túlio).

Sua fala corrobora uma das etapas de constituição da identidade profissional definida pelo relatório da Organisation for Economic Co-operation and Development (OECD, 2005, p. 10), segundo o qual a inserção do professor principiante acontece como etapa decisiva para o desenvolvimento de sua formação. Em semelhante interpretação, para Nóvoa (1992), a formação que engloba as "dimensões coletivas" contribui para uma emancipação profissional, dando autonomia para a construção de saberes e valores.

Em contrapartida, a docente Rúbia apresentou uma resposta que diverge dos entrevistados.

"Conheço vários profissionais, mas não tenho uma referência. Sempre busco ler artigos sobre o ensino de química de vários pesquisadores" (Rúbia).

Sua visão, assim como a do professor Túlio, nos mostra que os referenciais culturais para a constituição de identidade docente não precisam ser necessariamente pessoas, podendo ser experiências ou até mesmo obras da literatura do campo. Neste quesito, é provável que essas referências tenham uma relevância para a autoavaliação no âmbito de sua atuação profissional, bem como explica Marcelo $(2009$, p. 18) quando enuncia que "os professores aprendem quando têm a oportunidade de reflectir sobre o que fazem".

Os relatos apresentados até aqui possibilitam, por hora, uma visão parcial acerca de suas identidades únicas. Aprofundar em suas particularidades requer uma avaliação de experiências marcantes, seja de sua trajetória formativa ou profissional. Para tal, elencamos agora excertos de entrevistas que exploram experiências negativas e positivas relatadas pelos professores. Dentre elas, destaca-se:

"Uma experiência que me marcou muito foi a primeira semana de aula na universidade. Eu entrei no meio do primeiro semestre, no lugar da professora substituta. Quando dei a minha aula, os alunos pediam as referências de tudo o que eu falava, 'de quem é essa ideia professora', aí vi que mesmo acreditando nas ideias dos meus referenciais teóricos, a minha palavra somente não tinha valor para os alunos. Porque a área de ensino de 
ciências era desconhecida por eles, e primeira aula é complicado, você não conhece seu aluno... Ainda mais quando você entra em transição! E aí, eu já fui chegando e querendo jogar aquele monte de teoria na cabeça deles, ao invés de perguntar o que eles já sabiam e o que já tinham visto... tive que parar tudo, porque senão eles iam achar que era tudo da minha cabeça. Essa mesma turma, quando se formou me homenageou dando o meu nome para turma. Acredito que a docência é um ato de conquista" (Lídia).

Ao apresentar essa situação, a professora evidencia o aprendizado pela ação pedagógica, que Tardif (2005) classifica como um saber experiencial, proveniente de sua própria experiência diante da atuação em sala de aula. Esse tipo de saber docente só é adquirido pela prática do trabalho. Uma situação semelhante aparece também na entrevista com Cássia:

"Fiz uma proposta bastante transdisciplinar envolvendo uma parceria com o Museu Lasar Segall e os alunos não gostaram. Eram calouros e queriam um ensino de química conteudista e bancário, foi um choque para mim! Foi a partir dessa experiência que entendi que muitas vezes temos a retórica da interdisciplinaridade, pois sofri uma rejeição dos alunos, pela primeira vez na vida, e foi muito marcante! Eu peguei um grupo de alunos que veio de uma extrema fragmentação e competitividade, muito voltada para o vestibular. E eu entendi que não se pode partir para transdisciplinaridade direto sem fazer uma transição, eu fiz a minha autocrítica... Hoje considero positiva, na época foi dolorido, mas depois de grande experiência como educadora, eu cresci como educadora, porque hoje eu procuro conhecer mais a turma, entender os processos, e isso é fundamental" (Cássia).

Nesse relato, além do saber experiencial, há um destaque para a tentativa de introduzir uma metodologia nova para os alunos. A experiência de Cássia e aquela citada por Lídia convergem no que diz respeito aos conhecimentos prévios dos alunos. Além disso, o episódio narrado pela professora Cássia nos evidencia a singularidade e a imprevisibilidade dos alunos, assim como a importância de darmos voz a eles para que possam participar de nossas decisões, conhecer novas visões de mundo e se engajar no processo de ensino e de aprendizagem.

Por fim, dentre as experiências negativas, distingue-se a vivência da educadora Rute.

"Um professor que era referência na área de pesquisa, mas que não fazia questão de ensinar para seus estudantes. Além disso, ele era preconceituoso com mulheres e por várias vezes que fui tirar dúvidas na sala dele fui maltratada, com termos como 'Você não deveria estar aqui, seu lugar é lavando louça e esquentando o umbigo no fogão'. Apesar de todas as situações constrangedoras, eu segui em frente e consegui, entre poucos da turma, ser aprovada na disciplina" (Rute). 
O machismo e a misoginia presentes em sua descrição caracterizam um discurso que visa inferiorizar a mulher e se mostra como um produto de uma cultura cujas representações são machistas e sexistas. Pavan (2013, p. 108) concebe o professor "como um efeito dos discursos e das representações", portanto, suas vivências culturais o constroem e é preciso questionar a construção social das identidades de gênero para atingir mudanças pedagógicosociais.

As mudanças passam pelo questionamento das representações hegemônicas de gênero que circulam na cultura e na sociedade, isto é, teremos professores diferentes se conseguirmos subverter, mudar ou, ainda, pluralizar as representações, já que são elas que nos produzem como sujeitos (PAVAN, 2013, p. 108).

Apesar das recordações classificadas como ruins, os docentes carregam consigo muitas histórias e momentos ditos positivos em sua atuação e formação.

"A que eu destaco são os projetos de aulas práticas desenvolvidos com 40 estudantes por classe nos laboratórios de química... Quando a aula é interessante e os alunos estão envolvidos no processo, eles fazem e a coisa funciona! Cito o laboratório porque é uma coisa complexa, envolve deslocamento, mexer com material e reagente. Mas funcionava muito bem e foi uma experiência bacana, pois mostra que, quando você faz algo diferente que toca o estudante, aquilo tem grandes chances de funcionar" (Túlio).

Esse relato expõe a atuação do professor enquanto diferencial no processo de aprendizagem docente. Brito $(2012$, p. 2) propõe "que nós professores despertemos [a] sede de busca que pode levar a dois tipos de aprendizagem: superficial e profunda". A fala do professor Túlio pressupõe que essa forma de trabalho, que é capaz de gerar grande envolvimento, é uma boa forma de guiar suas ações e gerar um saber profundo, pois os alunos buscam o conhecimento e fazem relações com outros saberes. É, justamente, esse saber profundo que Clara cita:

"Um professor da pós-graduação que adora ciências, ele adorava o que fazia e demonstrava isso, a aula dele era encantadora... Ele é um professor pesquisador, e acho que, quando o professor é um professor-pesquisador, o que ele traz da formação como pesquisador por anos de pesquisa faz uma diferença em sala de aula. E, apesar de, geralmente, darem aulas mais expositivas, trazem um aprofundamento do conteúdo para a aula e isso tem um ganho na aprendizagem dos alunos. Ele não trazia metodologias modernas... ia lá e aplicava a aula na lousa, nos slides... e, como sabia com profundidade, isso fazia com que eu tivesse mais curiosidade sobre o assunto" (Clara). 
No entanto, alcançar certos patamares de profissionalidade exige tempo, dedicação e reflexão sobre a própria prática. $O$ início do desenvolvimento docente não é exclusivo da formação inicial, mas é o período que configura muitas das crenças que os futuros professores têm sobre o ensino (MARCELO, 2009). As vivências de Rúbia provam essa modificação nos professores em formação.

"Ao longo dos anos percebo que os alunos no início ficam angustiados com as etapas na formação, mas ao final é possivel observar que eles passam a trabalhar com os conteúdos aplicando tudo o que foi trabalhado ao longo dos anos. Considero isso muito positivo, pois demonstra que não se constrói nada em um semestre, é preciso dedicação e interação de vários anos" (Rúbia).

Há entre os entrevistados um anseio por manter-se fiel aos seus ideais. A professora Lídia cita a coerência como sua principal virtude em sala de aula, alinhando as ações aos seus ensinamentos, como uma forma de agir e de ensinar pelo exemplo. $E$, apesar de todos demonstrarem uma forma diferente de pensar a formação e a docência, o grupo assume, cada um de sua maneira, essa consciência visando alinhar os seus ideais pessoais e profissionais.

Todas essas experiências indicam as ideias que os professores carregam sobre si e sobre suas práticas, suas visões delimitam atitudes ideais e maneiras de guiar suas ações. "O professor é a pessoa e a pessoa é parte importante do professor" (NÓVOA, 1995, p. 25), deste modo, sua identidade se constrói a partir de suas vivências e é o resultado da junção das dimensões pessoal e profissional.

Esse trabalho requer grande competência emocional e profissional, pois está constantemente envolvido em problemas "dos e para os outros" (MUNSBERG; SILVA, 2014, p. 2), o que também requer uma associação íntima com sua pessoalidade. Além disso, exige uma consciência de que os alunos estão em constantes mudanças, bem como a própria forma de agir do professor.

\section{CONSIDERAÇÕES FINAIS}

A profissão docente tem notável exclusividade, visto que requer um trabalho único e muito específico, cercado por saberes e competências singulares. Entender tais especificidades é necessário para elucidar o papel social do professor e, principalmente, da construção de sua identidade, uma vez que o mundo contemporâneo "corrobora a proletarização do trabalho do/a professor/a, com reflexos negativos na qualidade do ensino e na própria identidade profissional docente" (MUNSBERG; SILVA, 2014, p. 7). 
Para investigar essa especificidade, a pergunta que norteou o presente trabalho foi: A partir de sua própria trajetória de formação e atuação no curso de licenciatura, como professores formadores entendem o profissional docente e sua formação? Para responder essa pergunta, foram entrevistados seis professores de um curso de licenciatura em Ciências de uma universidade pública do estado de São Paulo.

As análises dos relatos apontam para uma valorização da formação inicial, como etapa de apropriação das teorias e da articulação prática, momento em que os futuros professores tomam para si algumas referências de atuação e se apoderam de saberes específicos, saberes pedagógicos e saberes curriculares.

Suas concepções fortalecem a relevância das relações humanas na educação, considerada como um processo de troca constante entre educadores e alunos. Para isso, cabe ao professor grande entrega e reflexão sobre suas ações, bem como um profundo entendimento de seus ideais pessoais e de sua identidade.

Por se constituir como uma profissão única, sua identidade se constrói de diversos fatores, que se traduzem na história de vida individual, da sociedade que cerca os docentes, das instituições em que se formaram e trabalharam, dos professores que os ensinaram e dos alunos para os quais lecionaram (TARDIF, 2005).

Por fim, a identidade docente se mostra como um elemento primordial e crucial para o processo de aprendizagem dos professores formadores. Aprofundar-se nesta área requer uma análise minuciosa do que significa aprender e ensinar para ambas as partes.

\section{REFERÊNCIAS}

BARDIN, Laurence. Análise de conteúdo. Lisboa: Edições 70, 2004.

BELO, Edileusa do Socorro Valente; GONÇALVES, Tadeu Oliver. A identidade profissional do professor formador de professores de matemática. Revista Educação Matemática Pesquisa, São Paulo, v. 14, n. 2, p. 299-315, maio/ago. 2012. Disponível em:

https://revistas.pucsp.br/index.php/emp/article/view/9404. Acesso em: 20 jan. 2021.

BRITO, Rosa Maria Cavalcanti. O professor, a aprendizagem significativa e a avaliação: base para o sucesso escolar do aluno. In: SEMINÁRIOS REGIONAIS DA ANPAE, 7., 2012, Recife. Anais [...]. Recife, 2012. Disponível em:

https://www.seminariosregionaisanpae.net.br/numero1/1comunicacao/Eixo03_38/Rosa\%2 OMaria\%20Cavalcanti\%20Brito_int_GT3.pdf. Acesso em: 23 jan. 2021.

GATTI, Bernadete Angelina; BARRETTO, Elba Siqueira de Sá; ANDRÉ, Marli Eliza Dalmazo Afonso de. Políticas docentes no Brasil: um estado da arte. Brasília, DF: UNESCO, 2011. 
Visões de professores formadores sobre a formação e exercício da docência do professor de química

Gabrielle Gomes Ferreira, Thiago Antunes-Souza

GARCIA, Maria Manuela Alves; HYPOLITO, Álvaro Moreira; VIEIRA, Jarbas Santos. As identidades docentes como fabricação da docência. Educação e Pesquisa, São Paulo, v. 31, n. 1, p. 45-56, jan./abr. 2005. DOI: https://doi.org/10.1590/S1517-97022005000100004.

MARCELO, Carlos. Desenvolvimento profissional docente: passado e futuro. Revista de Ciências da Educação, São Paulo, n. 8, p. 7-22, jan./abr. 2009. Disponível em:

http://sisifo.ie.ulisboa.pt/index.php/sisifo/article/view/130. Acesso em: 23 nov. 2020.

MENDES, Thamiris Cristine; BACCON, Ana Lúcia Pereira. Profissão Docente: O que é ser Professor?. In: CONGRESSO NACIONAL DE EDUCAÇÃO, 12., 2015, Paraná. Anais [...]. Paraná: EDUCERE, 2015. p. 39786-39803. Disponível em:

https://educere.bruc.com.br/arquivo/pdf2015/17709_7650.pdf. Acesso em: 25 nov. 2020.

MIGUEL, Fernanda Valim Côrtes. A entrevista como instrumento para investigação em pesquisas qualitativas no campo da linguística aplicada. Revista Odisseia, Natal, n. 5, p. 1-11, jan./jun. 2012. Disponível em: http://www.periodicos.ufrn.br/odisseia/article/view/2029. Acesso em: 1 dez. 2020.

MINAYO, Maria Cecília de Souza. Trabalho de campo: contexto de observação, interação e descoberta. In: DESLANDES, Suely Ferreira; GOMES, Romeu; MINAYO, Maria Cecília de Souza (org.). Pesquisa social: teoria, método e criatividade. 27. ed. Petrópolis: Vozes, 2008. p. 6177.

MUNSBERG, João Alberto Steffen; SILVA, Denise Regina Quaresma da. Constituição docente: formação, identidade e professoralidade. In: SEMINÁRIO INTERNACIONAL DE EDUCAÇÃO, 14., 2014, Novo Hamburgo. Anais [...]. Novo Hamburgo: Universidade Feevale, 2014. p. 1-14. Disponível em: https://www.feevale.br/Comum/midias/c735bc84-d79f-4e7a-9ef351415c94f684/CONSTITUI\%C3\%87\%C3\%830\%20DOCENTE\%2OFORMA\%C3\%87\%C3\%830,\% 20IDENTIDADE\%20E\%20PROFESSORALIDADE.pdf. Acesso em: 25 nov. 2020.

NÓVOA, António. Formação de professores e profissão docente. In: NÓVOA, António (coord.). Os Professores e a sua Formação. Lisboa: Dom Quixote, 1992. p. 13-33.

NÓVOA, António. Profissão professor. 2. ed. Porto: Porto Editora, 1995.NÓVOA, António. Firmar a posição como professor, afirmar a profissão docente. Cadernos de Pesquisa, São Paulo, v. 47, n. 166, p. 1106-1133, 2017. DOI: https://doi.org/10.1590/198053144843.

NÓVOA, António. Firmar a posição como professor, afirmar a profissão docente. Cadernos de Pesquisa, São Paulo, v. 47, n. 166, p. 1106-1133, 2017. DOI:

https://doi.org/10.1590/198053144843.

ORGANISATION FOR ECONOMIC CO-OPERATION AND DEVELOPMENT. Teachers matter: attracting, developing and retaining effective teachers. Education and Training Policy. Paris: OECD Publishing, 2005. 12 p. DOI: https://doi.org/10.1787/9789264018044-en. Disponível em: https://www.oecd.org/education/school/34990905.pdf. Acesso em: 28 jan. 2021. 
PAVAN, Ruth. Currículo, a construção das identidades de gênero e a formação dos professores. Revista Contrapontos - Eletrônica, v. 13, n. 2, p. 102-109, maio/ago. 2013. DOI: https://doi.org/10.14210/contrapontos.v13n2.p102-109.

ROLDÃO, Maria do Céu. Função docente: natureza e construção do conhecimento profissional. Revista Brasileira de Educação, Rio de Janeiro, v. 12, n. 34, p. 94-103, abr. 2007. DOI: https://doi.org/10.1590/S1413-24782007000100008.

SANTOS FILHO, José Camilo dos. Pesquisa quantitativa versus pesquisa qualitativa: o desafio paradigmático. In: GAMBOA, Silvio Sánchez (org.). Pesquisa Educacional: quantidadequalidade. 5. ed. São Paulo: Cortez, 2002.

SCHNETLZER, Roseli Pacheco; ANTUNES-SOUZA, Thiago. A. O desenvolvimento da pesquisa em educação e o seu reconhecimento no campo científico da química. Educação Química en Punto de Vista, Foz do Iguaçu, v. 2, n. 1, p. 1-19, 2018. DOI:

https://doi.org/10.30705/eqpv.v2i1.1049.

SILVA, Osmair Benedito da; QUEIROZ, Salete Linhares. Mapeamento da pesquisa no campo da formação de professores de química no Brasil. Investigações em Ensino de Ciências, v. 21, n. 1, p. 62-93, mar. 2016. DOI: http://dx.doi.org/10.22600/1518-8795.ienci2016v21n1p62.

TARDIF, Maurice. Saberes docentes e formação profissional. Petrópolis: Vozes, 2005.

VALLE, Ione Ribeiro. Carreira do magistério: uma escolha profissional deliberada?. Revista Brasileira de Estudos Pedagógicos, Brasília, v. 87, n. 216, p. 178-187, maio/ago. 2006. DOI: https://doi.org/10.24109/2176-6681.rbep.87i216.792.

\section{Gabrielle Gomes Ferreira}

Graduada em Ciências - Habilitação em Química pela Universidade Federal de São Paulo, campus Diadema. Professora de Química para ensino médio.

ferreira.gabriellegomes@gmail.com

\section{Thiago Antunes-Souza}

Professor adjunto da Universidade Federal de São Paulo atuando no curso de Ciências Licenciatura do campus Diadema. Formado em Química-Licenciatura pela Universidade Metodista de Piracicaba e doutor em Educação pela mesma instituição, dedica-se ao campo de pesquisa e estudos da formação inicial e continuada de professores de química.

tasouza@unifesp.br 